\title{
A microeconomic foundation for optimal money laundering policies
}

\author{
Maryam Imanpour $^{\mathrm{a}, \mathrm{b}, *}$, Stephanie Rosenkranz ${ }^{\mathrm{a}}$, Bastian Westbrock ${ }^{\mathrm{a}}$, Brigitte Unger ${ }^{\mathrm{a}}$, \\ Joras Ferwerda ${ }^{a}$ \\ a Utrecht School of Economics, Utrecht University, the Netherlands \\ ${ }^{\mathrm{b}}$ Gonbad Kavous University, Iran
}

\section{A R T I C L E I N F O}

\section{Article history:}

Received 20 September 2018

Received in revised form 17 August 2019

Accepted 29 August 2019

Available online 31 August 2019

\section{Keywords:}

Money laundering

Social networks

Anti-money laundering policy

\begin{abstract}
A B S T R A C T
In this paper, we present a game-theoretic analysis of social networks in the money laundering process. In our model, criminals compete against each other in a crime market, but collaborate with other criminals and "dishonest" workers in the attempt to launder their crime proceeds via covert money laundering ties. Our first result shows that in the equilibrium money laundering network, a core group of criminals spreads its total crime proceeds over as many money launderers as available, giving rise to a core-periphery network where the size of the core group depends on the relative profitability of crime versus the outside option wage. We then study the optimal decision of a law enforcement agency that aims to minimize the total criminal activity in this society. We derive an optimal sharing rule that shows how much of a given crime-fighting budget the agency should optimally spend on anti-crime and antimoney laundering policies, respectively. This budget-sharing rule can be quantified empirically using readily available estimates for the expected crime proceeds, outside option wages, and fines in a society. Our predictions for four European countries (Sweden, the Netherlands, Poland, and Spain) show that the optimal budget share spent on money laundering controls should be about $35 \%$.
\end{abstract}

(C) 2019 Elsevier Inc. All rights reserved.

\section{Introduction}

In this paper, we present a game-theoretic analysis of social networks in the money laundering process. Our first objective is to develop a tractable model of a society of criminals and money launderers. In the model we propose, agents first choose to either enter the crime market or to pick up a legal job. Those who opt for a criminal career can subsequently form money laundering ties with every other active criminal and every "dishonest" worker, that is, every other agent who dropped out of the crime market. These ties help criminals to launder their anticipated crime proceeds, thereby reducing the probability that criminals are detected and prosecuted for a criminal act. Criminals, finally, determine their actual level of criminal activity, whereby they compete with other criminals for a booty of a fixed size. Our main finding on this game is that it has a unique subgame perfect Nash equilibrium when the costs of forming money laundering ties, which mainly consist of the risk of being detected and punished as a money launderer, are "not too high". In this equilibrium, a core-periphery network emerges that connects all active criminals with every other criminal agent in the soci-

\footnotetext{
* Corresponding author.

E-mail address: maryamimanpour@gmail.com (M. Imanpour).
}

ety. The equilibrium network thus shares some important features with real money laundering organizations in that the network is non-hierarchical and connects different criminals with each other (Kleemans, 2007). ${ }^{1}$

The second objective of our paper is to develop some policy recommendations from this model. Towards this end, we introduce a law enforcement agency into the model whose main objective it is to minimize the total level of criminal activity in the society. Nevertheless, in order to do so, the agency might proceed in two different ways: First, by directly increasing the probability of detecting criminal offenders in flagrante or, second, by making it harder for criminals to launder their crime proceeds, thereby deterring agents from entering the crime market. Our main result is an optimal sharing rule that shows how much of a given crime-fighting budget the agency should optimally spend on the fight against crime and money laundering, respectively (Fig. 1).

\footnotetext{
1 While criminal organizations often have hierarchical structures, such as Cosa Nostra, 'Ndrangetha, the Yakuza, and the Triads (Catino, 2014, 2019; Calderoni, 2015; Hill, 2003; Paoli, 2003; Wang, 2017), money laundering operations typically take place outside these hierarchies. According to Kleemans (2007), for example, a non-hierarchal, horizontal form of organization is the predominant form of organized crime in the Netherlands.
} 


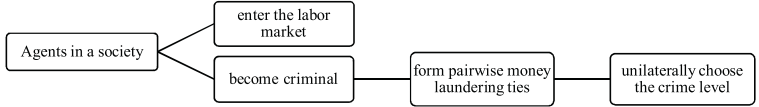

Fig. 1. The money laundering game.

To illustrate the use of this rule, we calculate the optimal budget shares for four European countries (Sweden, the Netherlands, Poland, and Spain). For this purpose, we take guidance from our model and use the fact that the optimal budget shares, as predicted by our model, depend solely on a few "sufficient statistics" (Chetty, 2009), that is, constructs of parameters and variables that have some immediate real-world correspondences. In particular, we show that one needs no more than readily available estimates for gross crime proceeds, the costs of money laundering activities, the expected fines on crime and money laundering felonies, and criminals' outside option wages in the legal economy to determine the optimal budget shares. Our best estimate for the optimal share to be spent on money laundering controls is about 35\% for all the four countries considered. Moreover, a sensitivity analysis shows that this value varies between $20.7 \%$ and $47.9 \%$ for all reasonable values of the required statistics, suggesting a robust and sizable crime deterrence effect of money laundering controls.

Our paper contributes to several strands in the economics literature on crime, money laundering, and social networks. First, our model is inspired by applications of network theory in industrial organization, in particular the game-theoretic model of Goyal and Joshi (2003) on the formation of inter-firm alliance networks. The key contribution of our paper to this literature is the endogenization of the crime-market entry choice, which naturally arises in our context and is common to crime models since the seminal work by Becker (1968). In this regard, our model is also closely related to other recent extensions of Becker's original model that look at the role of asset forfeiture (see e.g., Bowles et al., 2000; Miceli and Johnson, 2016) or money laundering (see e.g., Ferwerda, 2009) in this framework.

Second, our policy analysis comes closest to other recent applications of network theory to crime, in particular the key player policies developed in Ballester et al. (2006). The authors develop a simple sufficient statistic to identify the key player in a given network of agents who make their optimal activity levels dependent on the activity levels of their neighbors in the network. In their definition, the key player is the agent who once removed, leads to the largest reduction in aggregate activity. In our model, in contrast, the network is endogenously formed, whereby in equilibrium all criminals are equally central. It is thus optimal for a law enforcement agency to randomly target all agents and their network connections in our context.

Third, our policy analysis is also related to the model of Gaigné and Zenou (2015) who theoretically show that an increase in the budget spent on fighting crime (financed by a tax increase) can have an ambiguous effect. On the one hand, the additional money spent on police forces has a direct crime reducing effect. On the other hand, the additional tax may force people into crime, as their net incomes decrease. Just like in their model, we also consider one of the typical trade-offs that a law enforcement agency has to face. Different from their paper, this is the decision of how much money to optimally spend on several alternative policies to fight crime in our case.

The remainder of the paper is organized as follows. Section 2 sets out the model. Section 3 solves it. Section 4 derives the optimal budget-sharing rule, which is illustrated in Section 5 for four European countries. Section 6 concludes.

\section{The model}

Consider the following three-stage complete information game in a society of $n \geq 3$ agents $^{2}$ :

- In the first stage, every agent unilaterally decides whether to start a legal career as a "dishonest" worker or whether to enter the crime market. In particular, agents choose a criminal career because they expect to make more money than when following a legal occupation.

- In the second stage, agents who have started a criminal career now decide whether they want to form money laundering ties with every other active criminal or with every dishonest worker in the society. These links are pair-wise and costly and help criminals to disguise the source of their crime proceeds as some legal financial transaction.

- Finally, in the third stage, all active criminals unilaterally choose their crime effort levels. These efforts determine their actual gross proceeds earned in the crime market. The earnings are collected at the end of this stage where also all policies become effective and where it is determined whether an offender is detected and fined. All decisions upfront are thus in terms of expected payoffs.

\subsection{Notation}

Let $N=\{1,2, \ldots, n\}, n \geq 3$, denote the set of agents in the society. Agents who become criminal are members of subset $S \square N$. Agents who become workers are members of the complementary subset $N \backslash S$. Let $i$ and $j$ denote two typical members of the society. A money laundering link between them is described by the binary variable $g_{i j} \in\{0,1\}$. We say that agent $i$ has a money laundering link with agent $j$ when $g_{i j}=1$; agent $i$ has no such link with $j$ when $g_{i j}=0$. Links are assumed to be reciprocal (non-directed), so that $g_{i j}=g_{j i}$. Moreover, no agent has a money laundering link with herself, i.e., $g_{i i}=0$.

A network $g=\left\{\left(g_{i j}\right)_{i, j \in N}\right\}$ is the set of all money laundering links that exist between the agents. Let $g+g_{i j}$ denote the network obtained from network $g$ by replacing $g_{i j}=0$ in network $g$ by $g_{i j}=1$. Similar, let and $g-g_{i j}$ denote the network obtained by replacing $g_{i j}=1$ in network $g$ by $g_{i j}=0$. We will write $N_{i}(g)=$ $\left\{j \in N \backslash\{i\}: g_{i j}=1\right\}$ to denote the set of agents that share a money laundering link with agent, and $\eta_{i}(g)=\left|N_{i}(g)\right|$ the size of this set, which we also call agent $i$ ' s degree in network $g$.

We now define two networks that play a prominent role in our analysis. The complete network, $g^{c}$, is the network in which all agents are linked with each other: $g_{i j}=1 \forall i, j \in N$. The inter-link star architecture (Goyal and Joshi, 2003) defines a network consisting of a group of central agents who are connected to every other agent in the society, and a group of peripheral agents who are only connected to the centers. Formally, the inter-linked star partitions the set of agents into two groups, $\left\{h_{1}(g), h_{2}(g)\right\}$, which satisfies the following two properties:

(i) $N_{i}(g)=N \backslash\{i\}$ for all $i \in h_{2}(g)$, such that $\eta_{i}(g)=n-1$ for all central agents, and

(ii) $N_{j}(g)=h_{2}(g)$ for all $j \in h_{1}(g)$, such that $\eta_{j}(g)=\left|h_{2}(g)\right|$ for all peripheral agents.

\footnotetext{
2 The assumption of complete information implies that every agent knows the payoff functions and available strategies of all other agents. This entails that dishonest workers are aware of the fact that they perform illegal money laundering operations.
} 


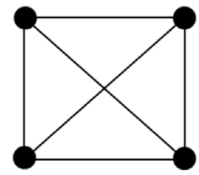

(a)

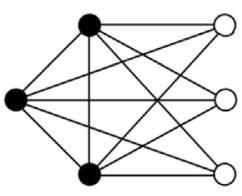

(c)

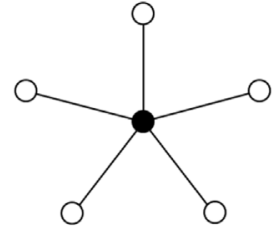

(b)

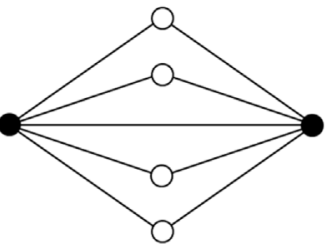

(d)
Fig. 2. Equilibrium money laundering networks.

The complete network and three inter-linked star architectures are illustrated in Fig. 2. Panel 2(b) shows the special case of a star network with only one agent in the center. Panels 2(c) and 2(d) then illustrate more general cases of inter-linked stars with multiple agents in the center.

\subsection{The payoffs}

In the first stage of the game, agents choose to either become criminal or to follow a legal occupation as an outside option. Agents with a legal occupation earn a fixed wage $\omega>0$. Agents with a criminal occupation earn an expected payoff. This payoff is, in a first instance, determined by the size of the booty, which shall be denoted by $y_{i}>0$ for criminal. Second, criminals face the risk of detection and punishment, whereby $E\left[F_{i}\right]$ denotes their expected penalty (in monetary terms). Third, criminals benefit from being connected with other agents in the society because every single link allows them to launder their crime proceeds. In return, however, the money launderer expects some transfer payment because the link comes at the risk of detection and prosecution for money laundering. We denoted the (possibly negative) transfer offered by agent $i$ to agent $j$ by $t_{i}^{j}$. Thus, in sum, the expected payoff of a typical agent $i$ is given by

$$
\begin{gathered}
E\left[\Pi_{i}\right]=E\left[\pi_{i}\right]-\sum_{j \in N \backslash\{i\}} t_{i}^{j} \\
= \begin{cases}y_{i}-E\left[F_{i}\right]-\sum_{j \in N \backslash\{i\}} t_{i}^{j} & \text { if } i \text { is a criminal } \\
\omega-E\left[F_{i}^{w}\right]-\sum_{j \in N \backslash\{i\}} t_{i}^{j} & \text { if } i \text { is a worker }\end{cases}
\end{gathered}
$$

where $E\left[F_{i}^{w}\right]$ denotes the fine a dishonest worker expects to pay for her money laundering activities.

In order to make the model more tractable, we further specify payoff function (1) as follows: First, we think of the crime proceeds, $y_{i}$, as the booty a criminal earns in an oligopolistic crime market. Consider, for example, the market for drug trafficking. ${ }^{3}$ Criminals

\footnotetext{
3 The predicate crimes that generate most of the crime money laundered are, indeed, drug dealing and fraud (see e.g., Walker, 1995; Walker and Unger, 2009; Unger et al., 2006, 2018). However, a significant part of the money derived from fraud offences is not in cash (one can think of investment fraud, where the money is normally transferred to the fraudulent investor electronically). Therefore, we see drug dealing as the primary source of income in our model. In particular, we consider a drug market with a stable demand curve and oligopolistic competition between sellers (in line with e.g. Poret, 2002) so that the price is a declining function of the total supply of drugs.
}

spend hours in a park or a street to sell their drugs. Suppose that two drug dealers try to sell their drugs in the same park. If one of them spends longer hours, he attracts more people to buy his drugs, his income will increase, while his rival's income will decrease. Formally, let $e_{i}$ denote the criminal effort of agent $i, \alpha$ the size of the crime market, and $\beta$ a slope parameter, where $e_{i} \geq 0$ and $\alpha, \beta>0{ }^{4}$ Gross crime proceeds are given as follows

$y_{i}=e_{i}\left(\alpha-\beta \sum_{j \in S} e_{j}\right)$

Second, criminals form money laundering ties with other criminals or dishonest workers to launder their crime proceeds, yet at the risk that their money laundering operation is detected. To formalize these costs and benefits of a money laundering link, we split the expected fine in formula (1) into two components: the expected fine on criminal felonies and the expected fine on pursuing money laundering activities, $E\left[F_{i}\right]=E\left[F_{i}^{c}\right]+E\left[F_{i}^{m}\right]$. The first term is proportional to the effort invested in drug dealing, the second one to the number of money laundering ties a criminal has. Let $\phi_{c}=p_{c} f_{c}$ denote the expected marginal cost of investing one unit of effort when a criminal has no money laundering ties. We assume that this cost is declining in the number of money laundering links a criminal has because each additional link allows him to split up ("smurf" in the money laundering jargon) his crime proceeds over more unsuspiciously-looking small financial transactions. ${ }^{5}$ To formalize this notion, we introduce a reporting threshold parameter $\gamma>0$, which measures the amount of transferable that still looks "unsuspicious". For example, in the US such a reporting threshold is 10,000 USD, while in the Netherlands it is 15,000 Euro. ${ }^{6}$ Technically, the parameter $\gamma$ defines how many cents of each dollar earned a criminal can disguise by means of each of his money laundering connections. In our model, the fine a criminal expects to pay for his criminal felonies is thus given by

$E\left[F_{i}^{c}\right]=\phi_{c} e_{i}\left(1-\gamma \eta_{i}(g)\right)$

whereby we additionally assume that $0<\gamma<\frac{1}{n-1}$, so that the expected fine is positive regardless of how well connected a criminal is. Note also that this implies that (a) the more active a criminal ( $e_{i}$ is larger), (b) the larger the reporting threshold $(\gamma)$, and (c) the larger the expected sanction $\left(\phi_{c}\right)$, the more it pays off to form money laundering ties.

Concerning the expected fines on money laundering, let $\phi_{m}=$ $p_{m} f_{m}$ denote the incremental cost of being involved into one money laundering link. Naturally, this cost is imposed on both agents involved in the link. Nevertheless, we assume that when a criminal is connected to another criminal to launder his money, the linking costs for this criminal are twice the costs of a link with a dishonest worker. The rationale is as follows: Criminals can only launder their money through a direct link with a dishonest worker who, for

\footnotetext{
${ }^{4}$ Imanpour (2017) develops a richer micro-foundation for the criminal "effort". Following Levitt and Dubner (2010)'s insights into the functioning of a drug cartel, she assumes that the effort represents the number of footsoldiers hired by a drug cartel. In her model, only a few traffickers make it to the top of a criminal organization, where they earn a large amount of money and thus have a demand for money laundering. The majority of traffickers, in contrast, works as footsoldiers at the bottom of the organization, where they make hardly sufficient money to survive and thus need additional sources of income or, as observed by Levitt and Dubner (2010), "live with their mothers".

5 Smurfing means the breaking down of cash deposits into small amounts that do not exceed a certain reporting threshold. Couriers ("smurfs") are typically used for this who make several small deposits at a number of banks (Reuter and Truman, 2004).

6 This reporting to the law enforcement agency is normally done indirectly. The observer, typically a bank, reports suspicious transactions to a central institution, the Financial Intelligence Unit, which filters out the relevant reports and forwards them to the relevant agency.
} 
instance, works in a bank. Hence, when they entrust their money to another criminal, the latter "channels" their money to their own connections in a bank. The chance of detection is thus twice as high as in the case of a direct link with a worker. In our model, the fine an agent expects to pay for his money laundering operations is thus given by

$$
\begin{cases}E\left[F_{i}^{m}\right]=\phi_{m}\left(2 \eta_{i}^{S}(g)+\eta_{i}^{N \backslash S}(g)\right) & \text { if } i \text { is a criminal } \\ E\left[F_{i}^{w}\right]=\phi_{m} \eta_{i}^{S}(g) & \text { if } i \text { is a worker }\end{cases}
$$

where $\eta_{i}^{S}(g)$ denotes the number of criminals who agent $i$ is connected to and $\eta_{i}^{N \backslash S}(g)$ the number of dishonest workers who agent $i$ is connected to. Moreover, we assume that the linking cost parameter $\phi_{m}$ is "not too large" as compared to the anticipated gains from money laundering. In particular, we assume that the net gains from a link with either another criminal or a dishonest worker are positive, even in the worst possible network configuration that a criminal can encounter in our game. Lemma 1 in the Supplementary Material shows that this entails the following parameter restriction:

$2 \phi_{m}<\frac{\phi_{c} \gamma(s-1)}{\beta^{2}(s+1)^{2}}\left(2\left(\alpha-\phi_{c}\right)-\phi_{c} \gamma(s-1)(2 n-5)\right)$

This, of course, requires some justification. Note that the assumption has some strong implications for the architecture of the equilibrium network because (5) implies that every active criminal prefers to form a link with every other agent in the society. Note, however, that the level of the linking cost still has a non-trivial impact on the number of agents starting a criminal career in our model because the higher the linking cost the lower the expected payoff from entering the crime market. Thus, despite of assumption (5), the level of the linking cost still determines the number of criminals in the network. At the same time, the advantage of this assumption over those made in earlier network formation models is that the equilibrium network architecture is unambiguously defined in our case. ${ }^{7}$

Third, and finally, we further specify the rules of how the costs and benefits of a money laundering link are shared in payoff function (1). Clearly, a dishonest worker would be willing to agree to a link as long as the transfer payment received by this agent at least compensates her for the linking $\operatorname{cost} E\left[F^{w}\right]$. We assume throughout that this is all she receives. In other words, all the bargaining power is on the criminal's side in the negotiation with a dishonest worker. On the other hand, when two criminals meet, we assume that they do not pass any side payments to each other because each of them benefits from the link directly. The expected criminal fine plus the compensatory payment a criminal has to make for a link are thus simply given by $2 \phi_{m} \eta_{i}(g)$, irrespective of whether he launders his money through another criminal or through a worker.

Thus, in sum, our assumptions lead to the following specification of payoff function (1):

$$
E\left[\Pi_{i} \mid e, g, s\right]
$$

\footnotetext{
7 The assumption is, in fact, essential for our policy analysis. A major issue with network formation models in general is that they are subject to multiple equilibria (see, e.g., Goyal and Joshi, 2003). As a consequence, it is typically hard to perform comparative static policy analysis for these models because even a small policy change might trigger an entirely different equilibrium network architecture. More concretely, let $\left\{g_{1}, g_{2}\right\}$ the set of equilibrium networks before the policy change and let $\left\{g_{1}^{\prime}, g_{2}^{\prime}\right\}$ denote the set of networks after the change. A change of policy to the initial network $g_{1}$ might lead to either $g_{1}^{\prime}$ or $g_{2}^{\prime}$, no matter how small the policy change was.
}

$$
=\left\{\begin{array}{c}
e_{i}\left(\alpha-\beta \sum_{j \in S} e_{j}\right)-\phi_{c} e_{i}\left(1-\gamma \eta_{i}(g)\right)-2 \phi_{m} \eta_{i}(g) \\
\quad \text { if } i \text { is a criminal } \\
\omega \quad \text { if } i \text { is a worker }
\end{array}\right.
$$

\section{Equilibrium}

Our solution concept is broadly speaking the subgame perfect Nash equilibrium. Nevertheless, we adopt some adjusted equilibrium concept because the formation of a link requires the mutual consent of the involved parties and criminals can pay some transfers to support their intent. We therefore draw on the network formation literature, in particular Goyal and Joshi (2003), to adopt an appropriate equilibrium concept for the second stage of our game.

Definition 1. A network $g$ is stable against transfers if:

$$
\begin{aligned}
& \text { (1) for all } \quad g_{i j}=1: E\left[\pi_{i} \mid g\right]-E\left[\pi_{i} \mid g-g_{i j}\right]+E\left[\pi_{j} \mid g\right]- \\
& E\left[\pi_{j} \mid g-g_{i j}\right]>0 \\
& \text { (2) for all } g_{i j}=0: E\left[\pi_{i} \mid g+g_{i j}\right]-E\left[\pi_{i} \mid g\right]+E\left[\pi_{j} \mid g+g_{i j}\right]- \\
& E\left[\pi_{j} \mid g\right]<0
\end{aligned}
$$

In words, a network $g$ is stable against transfers if the pairs of agents involved in any active link $\left(g_{i j}=1\right)$ see no reason to terminate it, and the pairs of agents who do not share a link $\left(g_{i j}=0\right)$ do not want to form it. In particular, since criminals can support their links by means of a transfer, and thus can compensate for the potential losses of their money launderers, all it requires to form a link between them is that the sum of their incremental link returns is positive.

The following result, which is proven in the Supplementary Material, provides a complete characterization of our game:

Proposition 1. Suppose that the payoff functions are given by (6) and suppose they satisfy condition (5). In every subgame perfect Nash equilibrium (in pure strategies), network $g^{*}$ is either the empty network, the complete network, or an inter-linked star with all active criminals in the center, $h_{2}\left(g^{*}\right)=S$, and all dishonest workers in the periphery, $h_{1}\left(g^{*}\right)=N / S$. Moreover, criminal efforts and payoffs are given by

$e^{*}(s)=\frac{\alpha-\phi_{c}\left(1-\phi_{c} \gamma(n-1)\right)}{\beta(s+1)}$ for all $i \in S$

$E\left[\Pi_{i} \mid s\right]= \begin{cases}\omega & \text { if } i \text { is a criminal } \\ \left(e^{*}(s)\right)^{2}-2 \phi_{m}(n-1) & \text { if } i \text { is a worker }\end{cases}$

Finally, the number of active criminals is given by

(i) when $\omega \geq E[\Pi \mid s=1]$, then every agent enters the labor market: $s^{*}=0$,

(ii) when $\omega \leq E[\Pi \mid s=n]$, then every agent becomes a criminal: $s^{*}=$ $n$,

(iii) when $E[\Pi \mid s=1]<\omega<E[\Pi \mid s=n]$, then the number of active criminals $\left(0 \leq s^{*}<n\right)$ is given by the largest integer value smaller than

$s^{\prime}=\frac{\alpha-\phi_{c}(1-\gamma(n-1))}{\beta \sqrt{\omega+2 \phi_{m}(n-1)}}-1$

where s' satisfies the condition: $E\left[\Pi_{i} \mid s^{\prime}\right]=\omega$.

In the equilibrium network, every active criminal is connected to every other agent in the society so that $\eta_{i}(g)=n-1$. Key to this result is the convexity of payoff function (6) with regard to money laundering ties: the incremental returns to link formation are increasing in the number of links a criminal already possesses in network $g$. The underlying intuition can be found in the "fine 


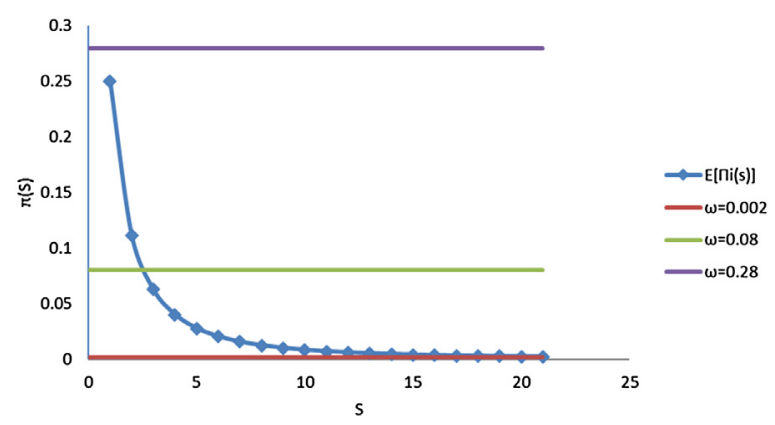

Fig. 3. Occupational decisions for different wage levels.

Notes: Crime proceeds (8) are calculated for $n=21, \phi_{m}=0.00001, \phi_{c}=0.5$, and $\gamma=0.05$.

for crime" expression (3): Every additional money laundering tie lowers the chance of being caught red-handed. As a result, every tie increases the incremental returns to criminal effort and thus perpetuates the level of criminal activity.

The role of the convexity property is thus similar to the "multiplier effect" of Masciandaro (1999) and Mackrell (1996). Money laundering accelerates criminal activity because it endows criminals with the capital they need to further expand their operations. In addition, however, our model predicts a "feedback effect" of crime on money laundering: Criminals anticipate on their high level of activity in the crime market and thus expect high returns to their money laundering ties. As a result, criminals form as many ties as they can so that the size of the equilibrium network is solely restricted by (a) the number of active criminals $s^{*}$ and (b) the number of available money launderers $n-1$.

Fig. 3 illustrates how the number of criminals $s^{*}$, and thus the size of the network, is determined for three possible wage levels. Generally, there is as much entry into the crime market until the expected crime proceeds of the last entrant are positive, and the expected proceeds of the next entrant would be negative. In particular, as the intensity of competition is increasing with every additional agent opting for a criminal career, the number of criminals is typically interior $\left(0<s^{*}<n\right)$ and the equilibrium network is typically an inter-linked star. The empty network $\left(s^{*}=0\right)$, or the complete network $\left(s^{*}=n\right)$, only emerge in the extreme cases where the criminal career is highly (un-)attractive as compared to the outside option wage.

\section{The optimal budget-sharing rule}

In the previous sections, we have built a tractable model of a criminal society. Here, we derive some policy recommendations from this model. In particular, we include an additional stage zero to the game on which a law enforcement agency aims to minimize the total level of criminal activity given a limited crime-fighting budget. The agency can make use of two policy instruments for this purpose: the expected fine on criminal felonies and the expected fine on money laundering activities $\left(\phi_{c}=p_{c} f_{c}\right.$ and $\left.\phi_{m}=p_{m} f_{m}\right)$. Following the convention in the money laundering literature (e.g., Reuter and Truman, 2004, or Ferwerda, 2012), the agency's objective is thus to fight predicate crimes, but in order to do so it can make use of anti-crime and anti-money laundering policies.

Optimality begets that the fines $f_{c}$ and $f_{m}$ are set at their maximum feasible values. These maxima may be given by the offender's wealth (i.e., a multiple of the crime proceed, $y_{i}$ ), such as in Becker (1968) or Garoupa (2000), or by any other moral or political constraint on the maximum penalty. Either way, we assume that the expected fines $\phi_{c}$ and $\phi_{m}$ are sufficiently small so that the society resides in one of the interior equilibrium points with $0<s^{*}<n$ of Proposition 1 Part (iii).
The agency's problem is, thus, to find some optimal values for the detection probabilities $p_{c}$ and $p_{m}$. From the previous section, we know that $p_{c}$ lowers the level of criminal activity directly by increasing the likelihood that a criminal offender is caught red-handed. The probability $p_{m}$ has, in contrast, only an indirect deterrence effect because it reduces in a first instance the prospects of successfully disguising the origins of a criminal's proceeds. We think of these probabilities as the outcomes of some investment that the agency can make into staff and equipment with the aim to monitor the agents and financial transactions in our society. Suppose, as of now, that the society consist of many agents. Some of them are the criminal agents introduced above, the others are "honest" workers who have a legal occupation.

The problem of the law enforcement agency is that it has, unlike all criminals, only imperfect information about the identity of all the other agents. The best the agency can thus do is to check people and financial transactions at random. It follows from this that the probability that a certain criminal agent is detected and caught is given by

$p_{c}=\frac{\theta_{c} b_{c}}{m}$

Likewise, the probability that a certain money laundering tie is detected among all the financial transactions in the society is given by

$p_{m}=\frac{\theta_{m} b_{m}}{m(m-1) / 2}$

where $b_{c}$ and $b_{m}$ denote the budget that the agency spends on its anti-crime and anti-money laundering policies, $\theta_{c}>0$ and $\theta_{m}>0$ denote some productivity parameters determining how a unit of investment translates into the probability of detection, $m$ denotes the total number of (legal and illegal) agents in the society $(m \geq n)$, and $m(m-1) / 2$ gives the total number of financial transactions. ${ }^{8}$

Accordingly, the agency's optimization problem is as follows

$$
\begin{array}{ll}
\text { subject to the constraints : } & b_{c}+b_{m} \leq B, \\
& b_{c} \geq 0, \text { and } b_{m} \geq 0
\end{array}
$$

For simplicity, we hereby assume that the number of active criminals is sufficiently large so that the integer value $s^{*}$ can reasonably be approximated by the real number $s^{\prime}$ defined in (9). ${ }^{9}$

Substituting the expressions in (7) and (9) into (10), the objective function becomes

$$
\begin{gathered}
\min _{b_{c}, b_{m}} L=\frac{\alpha-f_{c} \theta_{c} b_{c}(1-\gamma(n-1)) / m}{\beta} \\
-\sqrt{\omega+2 \frac{f_{m} \theta_{m} b_{m}(n-1)}{m(m-1) / 2}}
\end{gathered}
$$

where in optimum: $b_{c}=B-b_{m}$. Hence, the agency's problem reduces to a simple unconstrained minimization problem with $b_{m}$ as the sole variable. Solving this problem yields the following result, the proof of which can be found in the Supplementary Material:

Proposition 2. The optimal budget shares of a law enforcement agency are given as follows:

\section{(i) Anti-money laundering budget share}

\footnotetext{
${ }^{8}$ In particular, $m(m-1) / 2$ is the total number of undirected ties in a complete network between $m$ agents.

9 That assumption is common in the industrial organization literature (see, e.g., Mankiw and Whinston, 1986).
} 
$b_{m}^{*}=\frac{\frac{f_{m} \theta_{m}(n-1)}{m(m-1) / 2}}{2\left(\frac{f_{c} \theta_{c}(1-\gamma(n-1))}{m \beta}\right)^{2}}-\frac{\omega}{2 \frac{f_{m} \theta_{m}(n-1)}{m(m-1) / 2}}$

(i) Anti-crime budget share

$b_{c}^{*}=B-b_{m}^{*}$

This means that the optimal ratio of policies satisfies the following properties:

(i) when the reporting threshold $\gamma$ increases, anti-money laundering policies become relatively more important : $\partial\left(b_{c}^{*} / b_{m}^{*}\right) / \partial \gamma<0$,

(ii) when the wage rate $\omega$ increases, anti-crime policies become relatively more important: $\partial\left(b_{c}^{*} / b_{m}^{*}\right) / \partial \omega>0$,

(iii) $\theta_{c} f_{c}$ and $b_{c}^{*}$, as well as $\theta_{m} f_{m}$ and $b_{m}^{*}$ are complements.

The result has some interesting implications with policy relevance. In particular, part (iii) states that anti-money laundering policies are relatively more attractive in societies with a higher reporting threshold. The intuition is as follows: A high threshold implies that it is relatively easy to transfer larger chunks of money without the risk of filing an activity report. It is thus more difficult and costly to prosecute criminals for their felonies because the agency has less evidence to hold against them. Hence, it pays off to focus on money laundering controls and on the risk-based investigation of financial transactions, in particular of those below the reporting threshold.

Part (iv), in turn, suggests that in societies with a higher average wage rate, money laundering controls become relatively less attractive. A higher outside option wage implies that fewer agents enter the crime market, and that as a result also the number of money laundering ties go down. We know, however, from Proposition 1 that every active criminal has many ties. Hence, the number of illegal money laundering transactions goes down by even more than the number of criminals, so that a random investigation of transactions becomes relatively less attractive than chasing criminals directly. Thus, next to the well-known direct effect of wages on crime (Becker, 1968; Engelhardt et al., 2008), wages also play a role in the optimal allocation of resources to fight different types of crime.

Part (v), finally, states that the attractiveness of anti-crime (antimoney laundering) policies increases, the higher the effectiveness of the respective policy and the higher the penalty on this type of crime. At first sight, this seems at odds with the widely held view that a higher penalty on a certain type of crime should allow a law enforcement agency to slack on its prosecution because the overall deterrence effect will still be high (Becker, 1968). Nevertheless, there is no contradiction here because when the aim is to reduce a certain type of crime by means of different possible instruments, focusing on those instruments that are most effective in this regard maximizes the overall deterrence effect.

\section{Empirical application}

Having derived the optimal mix of policy instruments for our simple criminal society, we now illustrate the empirical usefulness of our model by determining the optimal budget shares for a number of countries. We thereby take advantage of the fact that our theoretical predictions allow us to significantly reduce the informational burden that usually plagues such an exercise. In particular, rather than needing to calibrate all the parameters of the model, it turns that all we need is easily obtainable data on a handful of variables.

\subsection{The sufficient statistics approach}

To see how one can express the optimal budget-sharing rule in terms of a few "sufficient statistics" (Chetty, 2009), let us start from expression (12), which defines the optimal budget share spent on money laundering controls. Making use of expressions (3) and (4), which define the expected punishments for crime and money laundering, respectively, we can rewrite identity (12) as

$b_{m}^{*}=\frac{\frac{E\left[F^{m}\right]+\text { trans }}{b_{m}^{*}}}{4\left(\frac{E\left[F^{c}\right]}{\beta b_{c}^{*} e^{*}}\right)^{2}}-\frac{\omega b_{m}^{*}}{E\left[F^{m}\right]+\text { trans }}$

where trans denotes the total amount of transfers paid by a typical criminal to all his money launderers as a compensation for their anticipated sanctions.

In a next step, let us make use of a well-known calculation trick from the industrial organization literature that in markets with a linear demand function the operating profits of a firm are identical to its squared output. Applied to our context, this means that

$$
\begin{aligned}
& y^{*}=e^{*}\left(\alpha-\beta s e^{*}\right)=e^{*}\left(\frac{\alpha+s \phi_{c}-s \phi_{c} \gamma(n-1)}{(s+1)}\right) \\
& =e^{*}\left(e^{*} \beta+\phi_{c}(1-\gamma(n-1))\right)=e^{*}\left(e^{*} \beta+\frac{E\left[F^{c}\right]}{e^{*}}\right)
\end{aligned}
$$

where we have made use of expressions (2), (3), and (7). Hence, $\left(e^{*}\right)^{2} \beta=y^{*}+E\left[F^{c}\right]$, and we can thus write

$$
b_{m}^{*}=\frac{\left(E\left[F^{m}\right]+\text { trans }\right)\left(y^{*}+E\left[F^{c}\right]\right)^{2}\left(b_{c}^{*}\right)^{2}}{4 b_{m}^{*}\left(E\left[F^{c}\right]\right)^{2}\left(e^{*}\right)^{2}}-\frac{\omega b_{m}^{*}}{E\left[F^{m}\right]+\text { trans }}
$$

In a final step, we make use of the fact that in equilibrium, agents are indifferent between a criminal and a legal career. The reason is that entry into the crime market takes place until the intensity of competition between the incumbents erodes any criminal rents. This implies, in a first instance, that

$y^{*}-E\left[F^{c}\right]-E\left[F^{m}\right]-$ trans $=\omega$

This also implies that the criminal efforts can be written as

$e^{*}=\sqrt{\omega+E\left[F^{m}\right]+\text { trans }}$

Applying condition (14) onto the optimal budget-share formula, we get

$b_{m}^{*}=\frac{\left(E\left[F^{m}\right]+\text { trans }\right)\left(y^{*}+E\left[F^{c}\right]\right)^{2}\left(b_{c}^{*}\right)^{2}}{4 b_{m}^{*}\left(E\left[F^{c}\right]\right)^{2}\left(\omega+E\left[F^{m}\right]+\text { trans }\right)}-\frac{\omega b_{m}^{*}}{\left(E\left[F^{m}\right]+\text { trans }\right)}$

or, after some transformations,

$\frac{b_{m}^{*}}{b_{c}^{*}}=\frac{\left(y^{*}+\left(E\left[F^{c}\right]\right)\right)\left(E\left[F^{m}\right]+\text { trans }\right)}{2 E\left[F^{c}\right]\left(\omega+E\left[F^{m}\right]+\text { trans }\right)}$

We thus arrive at an expression that relates the optimal policy ratio for a society to the expected fines on crime and money laundering felonies, the going wage rate, the gross crime proceeds, and the costs of money laundering ties in terms of compensatory payments. ${ }^{10}$ In other words, in order to quantify our budget-

\footnotetext{
10 Consistent with Proposition 2 Part (v), formula (15) thus states that the higher the expected fines on crime (money laundering), the lower (higher) the optima expenditure share going to money laundering controls. Similar, consistent with Part (iv), societies with a higher legal wage rate should dedicate more attention to combating crime. A new prediction from (15) is that societies with a larger crime market that is, a higher crime proceed $y^{*}$, should spend more money on money laundering controls. The argument is the flipside of the rationale leading to the wage effect. Societies with a larger crime market attract many criminals. However, as each crim-
} 
Table 1

Application of the budget-sharing rule to the Netherlands, Spain, Sweden and Poland.

\begin{tabular}{|c|c|c|c|c|c|}
\hline Variable & The Netherlands & Spain & Sweden & Poland & Source \\
\hline$P_{m}$ & $10 \%$ & $10 \%$ & $10 \%$ & $10 \%$ & Assumption \\
\hline$E\left[F^{m}\right]$ & $€ 14,138$ & $€ 8524$ & $€ 15,237$ & $€ 3,576$ & Unger et al. (2014) \\
\hline trans & $€ 6000$ & $€ 3618$ & $€ 6466$ & $€ 1,518$ & Soudijn and Reuter (2016) \\
\hline$y^{*}$ (drugs) & $€ 180,385$ & $€ 102,451$ & $€ 204,673$ & $€ 49,593$ & Unger et al. (2018) \\
\hline$\omega$ & $€ 23,563$ & $€ 14,207$ & $€ 25,395$ & $€ 5,960$ & Eurostat \\
\hline Optimal ratio $\left(\frac{b_{m}^{*}}{b_{c}^{*}}\right)$ & 0.53 & 0.54 & 0.53 & 0.53 & \\
\hline Optimal share $\left(\frac{b_{m}^{*}}{b_{c}^{*}+b_{m}^{*}}\right)$ & $34.8 \%$ & $35.1 \%$ & $34.6 \%$ & $34.5 \%$ & \\
\hline
\end{tabular}

sharing rule, one needs no more than readily available information on micro-constructs that measure the relative attractiveness of a criminal career versus a legal career. In fact, we can further reduce the informational requirements of (15) by making use of the second "no market entry"-condition (13). Depending on the data available, we are free to express one of the variables in (15) by means of the remaining four.

\subsection{Data and results}

To illustrate the usefulness of formula (15), we now apply it to four EU Member States: The Netherlands, Spain, Sweden, and Poland. The information needed for (15) is from the Eurostat EUSILC survey, the ECOLEF study, and the studies by Unger et al. (2018) and Soudijn and Reuter (2016).

It turns out that the hardest statistic to quantify is the expected fine on crime, $E\left[F^{c}\right]$. The available data subsumes several different types of crimes and it is difficult to discern which specific type they are related to. Moreover, even though we have crime statistics, different crimes get under- or over-estimated in an unknown manner in terms of the likelihood with which they are prosecuted. ${ }^{11}$ We therefore substitute $E\left[F^{c}\right]=y^{*}-\omega-E\left[F^{m}\right]-$ trans in expression (15) and quantify the remaining variables.

For the wage rate, $\omega$, we use the median-equivalized net income per household from the Eurostat EU-SILC survey. ${ }^{12}$ For the proceeds of crimes, $y^{*}$, we use the estimates of Unger et al. (2018). ${ }^{13}$ The most important predicate crimes for money laundering are drugs and fraud (see e.g., Walker, 1995; Walker and Unger, 2009; Unger et al., 2006, 2018). We therefore use the estimated incomes for drug-related crimes in our main specification and test the robustness of our results with regard to fraud incomes in our sensitivity analyses. For the money laundering compensations, trans, we do not have data for each country. Information about this only shows up every once in while in detected cases. An impressive study on payments for money laundering services is, however, presented in Soudijn and Reuter (2016). The authors analyze six big drug cases in the Netherlands and were able to present a detailed overview of their financial statements. We draw on their conclusion that "on average, a courier made $€ 6000$ " (Soudijn and Reuter, 2016, p.283) to quantify trans for the Netherlands. Moreover, we use the wage difference with the Netherlands to estimate the values of trans for Spain, Sweden and Poland. Regarding the expected money laundering fines, $E\left[F^{m}\right]=f_{m} p_{m}(n+s)$, we take advantage of the estimates

inal will form many more money laundering ties, the chance of hitting an illegal financial transaction by chance is much higher.

11 One would expect, for example, that crimes without a direct victim (drug trade, corruption, prostitution) get reported less often than when there is a direct victim (theft, burglary, murder).

12 Eurostat EU-SILC survey, 2017: http://appsso.eurostat.ec.europa.eu/nui/show. do?dataset=ilc_di04\&lang=en (accessed April 29, 2019).

13 We estimate $y^{*}$ by dividing the total money laundering demand per crime divided by the number of crimes for the latest year available, 2014.
Table 2

Sensitivity of the optimal budget-sharing rule spent on money laundering controls with regard to different values of the detection probability.

\begin{tabular}{lllll}
\hline \multirow{2}{*}{ Value for $P_{m}$} & \multicolumn{3}{l}{ Optimal budget shares $\left(\frac{b_{m}^{*}}{b_{c}^{*}+b_{m}^{*}}\right)$} & \\
\cline { 2 - 5 } & The Netherlands & Spain & Sweden & Poland \\
\hline $1 \%$ & $20.9 \%$ & $21.0 \%$ & $20.8 \%$ & $20.7 \%$ \\
$5 \%$ & $28.7 \%$ & $28.9 \%$ & $28.5 \%$ & $28.5 \%$ \\
$10 \%$ (as in Table 1) & $34.8 \%$ & $35.1 \%$ & $34.6 \%$ & $34.5 \%$ \\
$20 \%$ & $42.3 \%$ & $42.7 \%$ & $41.9 \%$ & $41.7 \%$ \\
$30 \%$ & $47.3 \%$ & $47.9 \%$ & $46.7 \%$ & $46.5 \%$ \\
\hline
\end{tabular}

from the ECOLEF ${ }^{14}$ study (Unger et al., 2014, p141) for $f_{m}$. These estimates include monetary fines and imprisonment. ${ }^{15}$ The other component, the detection probability $P_{m}=p_{m}(n+s)$, is by definition unknown. We use $10 \%$ for the purpose of illustration, but test the effect of other reasonable values for this variable $(1 \%, 5 \%, 20 \%$, and $30 \%$ ) in our sensitivity analyses.

Table 1 shows all the estimates we use for our calculations, as well as the optimal budget-sharing rules for the four countries we considered. The key finding from this table is that the optimal budget share to be spent on money laundering controls is robust and sizable: about $35 \%$ across all four countries.

Nevertheless, since we use estimates and not precise data for most of our required variables, the precise numbers in Table 1 have to be interpreted with care. To partially alleviate this concern, we conducted several sensitivity tests to see how our results change for slight, or even drastic, variations of the variable values. In particular, we tested the robustness of our findings with regard to different values for trans and $y^{*}$. Moreover, we used proceeds from fraud instead of drugs for $y^{*}$.

Below, we present the results on our testing of the most impactful variable, the detection probability, $P_{m}$. The complete set of findings on all our other sensitivity tests can be found in the Supplementary Material. To briefly summarize our findings here, it turns out, maybe surprisingly, that the results presented Table 1 are not very sensitive with regard to either of the input variables. Regardless of the variable values considered in our tests, the optimal budget share to be spent on money laundering controls always lies in the range of $20.7-47.9 \%$ (Table 2 ).

\footnotetext{
${ }^{14}$ ECOLEF is an EU financed project on the Economic and Legal Effectiveness of Anti-Money Laundering and Counter Terrorism Financing in the 27 EU Member States.

15 We convert prison time to monetary values by multiplying the number of years with twice the legal wage values we use (the median equivalized net income per household from the Eurostat EU-SILC survey). This is quite in line with Unger et al. (2014, p.142) for countries like the Netherlands and Sweden (Unger et al., 2014 uses 50,000 for all countries we use 47,126 and 50,790 for the Netherlands and Sweden respectively), but gives more realistic values for countries like Spain and Poland by taking into account the price level differences between the different countries.
} 


\section{Conclusions}

In this paper, we build a game theoretic model to inquire into criminals' incentives to form money laundering links, the effect of these links on the total level of criminal activity in a society, and the optimal policy response by a law enforcement agency.

Our first finding is a complete characterization of the money laundering network that emerges in the equilibrium of our model. Assuming that the costs of link formation are small, we show that the equilibrium network is either the empty network, the complete network or a core-periphery network, which crucially depends on the level of the outside option wage for our criminals. Nevertheless, for a given wage level, the equilibrium architecture is uniquely defined, which gives way to our second class of findings on the optimal policy response.

Money laundering researchers and policy makers agree that the ultimate objective of money laundering controls is to dry out and fight predicate crimes. The question we answer in this paper is which policies to focus on: crime or money laundering controls? In our model, we phrase this question in terms of how to optimally split up a given crime-fighting budget. We derive an optimal budget-sharing rule from our model and empirically illustrate its use at the example of four European countries. Our findings indicate a sizable and robust, indirect deterrence effect of money laundering controls for all four countries.

\section{Appendix A. Supplementary data}

Supplementary material related to this article can be found, in the online version, at doi:https://doi.org/10.1016/j.irle.2019. 105856 .

\section{References}

Ballester, C., Calvó-Armengol, A., Zenou, Y., 2006. Who's who in networks. Wanted: the key player. Econometrica 74 (5), 1403-1417.

Becker, G.S., 1968. Crime and punishment: an economic approach. In: The Economic Dimensions of Crime. Palgrave Macmillan, UK, pp. 13-68.

Bowles, R., Faure, M., Garoupa, N., 2000. Economic analysis of the removal of illegal gains. Int. Rev. Law Econ. 20 (4), 537-549.

Calderoni, F. 2015. Predicting organized crime leaders. In: Bichler G., Malm, A.E. (Eds.), Disrupting Criminal Networks: Network Analysis in Crime Prevention, Crime Prevention Studies. Lynne Rienner Publishers, Boulder, pp. 89-110.

Catino, M., 2014. How do mafias organize? Conflict and violence in three mafia organizations. Eur. J. Sociol./ Archives Européennes de Sociologie 55 (2), $177-220$.
Catino, M., 2019. Mafia Organizations: The Visible Hand of Criminal Enterprise. Cambridge University Press, Cambridge.

Chetty, R., 2009. Sufficient statistics for welfare analysis: a bridge between structural and reduced-form methods. Annu. Rev. Econom. 1 (1), 451-488.

Engelhardt, B., Rocheteau, G., Rupert, P., 2008. Crime and the labor market: a search model with optimal contracts. J. Public Econ. 92 (10), 1876-1891.

Ferwerda, J., 2009. The economics of crime and money laundering: does anti-money laundering policy reduce crime? Rev. Law Econ. 5 (2), 903-929.

Ferwerda, J., Doctoral dissertation 2012. The Multidisciplinary Economics of Money Laundering. Utrecht University.

Gaigné, C., Zenou, Y., 2015. Agglomeration, city size and crime. Eur. Econ. Rev. 80, 62-82.

Garoupa, N., 2000. The economics of organized crime and optimal law enforcement. Econ. Inq. 38 (2), 278-288.

Goyal, S., Joshi, S., 2003. Networks of collaboration in oligopoly. Games Econ. Behav. 43 (1), 57-85.

Hill, P.B.E., 2003. The Japanese Mafia: Yakuza, Law, and the State. Oxford University Press, Oxford.

Imanpour, M., Doctoral dissertation 2017. The Role of Social Networks for Combating Money Laundering. Utrecht University.

Kleemans, E.R., 2007. Organized crime, transit crime, and racketeering. Crime Justice 35 (1), 163-215.

Levitt, S.D., Dubner, S.J., 2010. Freakonomics, Vol. 61. Sperling \& Kupfer editori.

Mackrell, N., 1996. Economic consequences of money laundering. Res. Public Policy Ser. 29 (2).

Mankiw, N.G., Whinston, M.D., 1986. Free entry and social inefficiency. Rand J. Econ. 17 (1), 48-58.

Masciandaro, D., 1999. Money laundering: the economics of regulation. Eur. J. Law Econ. 7 (3), 225-240.

Miceli, T.J., Johnson, D., 2016. Asset forfeiture as a law enforcement tool. Contemp. Econ. Policy 34 (1), 119-126.

Paoli, L., 2003. Mafia Brotherhoods: Organized Crime, Italian Style. Oxford University Press, Oxford.

Poret, S., 2002. Paradoxical effects of law enforcement policies: the case of the illicit drug market. Int. Rev. Law Econ. 22 (4), 465-493.

Reuter, P., Truman, E.M., 2004. Chasing Dirty Money. Institute for International Economics.

Soudijn, M., Reuter, P., 2016. Cash and carry: the high cost of currency smuggling in the drug trade. Crime Law Soc. Change 66 (3), 271-290.

Unger, B., Siegel, M., Ferwerda, J., de Kruijf, W., Busuioic, M., Wokke, K., Rawlings, G., 2006. The amounts and the effects of money laundering. In: Report for Dutch Ministry of Finance.

Unger, B., Ferwerda, J., van den Broek, M., Deleanu, I., 2014. The Economic and Legal Effectiveness of the European Union's Anti-Money Laundering Policy. Edward Elgar Publishing.

Unger, B., Ferwerda, J., Koetsier, I., Gjoleka, B., van Saase, A., Slot, B., de Swart, L., 2018. Aard En Omvang Van Criminele Bestedingen (Nature and Scale of Criminal Spending), Report for Scientific Research and Documentation Centre. Dutch Ministry of Justice and Security.

Walker, J., 1995. Estimates of the extent of money laundering in and through Australia. Paper Prepared for Australian Transaction Reports and Analysis Centre.

Walker, J., Unger, B., 2009. Measuring global money laundering:the walker gravity model. Rev. Law Econ. 5 (2), 821-853.

Wang, P., 2017. The Chinese Mafia: Organized Crime, Corruption, and Extra-Legal Protection. Oxford University Press., Oxford 